\title{
BMJ Open A qualitative study of diverse providers' behaviour in response to commissioners, patients and innovators in England: research protocol
}

\author{
Rod Sheaff, ${ }^{1}$ Joyce Halliday, ${ }^{1}$ Mark Exworthy, ${ }^{2}$ Pauline Allen, ${ }^{3}$ Russell Mannion, ${ }^{2}$
} Sheena Asthana, ${ }^{1}$ Alex Gibson, ${ }^{1}$ Jonathan Clark ${ }^{1}$

To cite: Sheaff R, Halliday J, Exworthy M, et al. A qualitative study of diverse providers' behaviour in response to commissioners patients and innovators in England: research protocol. BMJ Open 2016;6:e010680. doi:10.1136/bmjopen-2015010680

- Prepublication history for this paper is available online To view these files please visit the journal online (http://dx.doi.org/10.1136/ bmjopen-2015-010680)

Received 26 November 2015 Revised 24 March 2016 Accepted 5 April 2016

\section{CrossMark}

${ }^{1}$ School of Government, Plymouth University, Plymouth, UK

${ }^{2}$ Health Services

Management Centre, School of Social Policy, University of Birmingham, Birmingham, UK

${ }^{3}$ Department of Health Services Research and Policy, London School of Hygiene and Tropical Medicine, London, UK

Correspondence to Professor Rod Sheaff; R.sheaff@plymouth.ac.uk

\section{ABSTRACT \\ Introduction: The variety of organisations providing National Health Service (NHS)-funded services in England is growing. Besides NHS hospitals and general practitioners (GPs), they include corporations, social enterprises, voluntary organisations and others. The degree to which these organisational types vary, however, in the ways they manage and provide services and in the outcomes for service quality, patient experience and innovation, remains unclear. This research will help those who commission NHS services select among the different types of organisation for different tasks.}

Research questions: The main research questions are how organisationally diverse NHS-funded service providers vary in their responsiveness to patient choice, NHS commissioning and policy changes; and their patterns of innovation. We aim to assess the implications for NHS commissioning and managerial practice which follow from these differences.

Methods and analysis: Systematic qualitative comparison across a purposive sample (c.12) of providers selected for maximum variety of organisational type, with qualitative studies of patient experience and choice (in the same sites). We focus is on NHS services heavily used by older people at high risk of hospital admission: community health services; out-of-hours primary care; and secondary care (planned orthopaedics or ophthalmology). The expected outputs will be evidence-based schemas showing how patterns of service development and delivery typically vary between different organisational types of provider.

Ethics, benefits and dissemination: We will ensure informants' organisational and individual anonymity when dealing with high profile case studies and a competitive health economy. The frail elderly is a key demographic sector with significant policy and financial implications. For NHS commissioners, patients, doctors and other stakeholders, the main outcome will be better knowledge about the relative merits of different kinds of healthcare provider. Dissemination will make use of strategies suggested by patient and public involvement, as well as $\mathrm{DH}$ and service-specific outlets.
Strengths and limitations of this study

- Addresses the policy relevant research issue of diverse provision of National Health Service (NHS)-funded services.

- Evidence-based schemas will show how different organisational types of provider vary in their typical patterns of service development and delivery.

- Research findings are expected to inform the NHS commissioning process, provider development policy and competition policy.

- This protocol does not include quantitative analysis of the patterns or consequences of diverse provision.

- It focuses on patients' experience of choice rather than on continuity and (other aspects of) quality of care under diverse provision.

\section{INTRODUCTION}

English health policy, particularly Equity and excellence: Liberating the $N H S,{ }^{1}$ any qualified provider (AQP) policy, and patient choice policy, ${ }^{2}$ aims to promote competition among existing NHS providers ${ }^{3}$ and the provision of NHS-funded services by diverse providers. These include corporations, professional partnerships, owner-managed small firms, social enterprises, cooperatives, voluntary organisations, NHS foundation trusts and various hybrids ${ }^{4}{ }^{5}$ such as having a "prime contractor' provider subcontract others ${ }^{6}$ and the accountable care organisations foreseen in the Five Year Forward View. ${ }^{7}$ Such variations in ownership ${ }^{8} 9$ and management ${ }^{10-12}$ raise questions about how these providers differ in their reactions to the different media of power which commissioners potentially exercise over them, ${ }^{13}$ hence differ in the ways that they implement health policy and NHS commissioners' aims; or indeed whether 
commissioners will constrain them all so narrowly as to allow little variation.

Studies of other sectoral and national contexts suggest that different types of provider may vary in the services produced, ${ }^{14}$ patient groups served, ${ }^{15-17}$ size, prices, ${ }^{15}{ }^{18-20}$ contractual flexibility, ${ }^{21}{ }^{22}$ transparency, ${ }^{23}$ responsiveness to financial incentives, ${ }^{24}{ }^{25}$ perceived trustworthiness, ${ }^{26}$ clinical outcomes ${ }^{27}$ and service quality. ${ }^{28} 29$ Different ownership might also predict different selections of innovations and technologies. ${ }^{30-33}$ These differences imply different responses to governments' and commissioners' power, to competition and competitors, patient and public participation, and inequalities in access. In contrast, other studies report different organisational types converging in productivity, managerial practices, ${ }^{34}{ }^{35}$ production costs ${ }^{36}$ and use of mergers. ${ }^{37}$ Providers with large market shares tend to set pricing and quality patterns for the whole health system, ${ }^{15}$ so the behaviour of different types of provider may depend partly on the overall mix ${ }^{38}$ and converge over time.

It is also unclear whether diverse providers react differently to their regulatory and policy environment (eg, the National Institute for Health and Care Excellence (NICE) guidance and the Francis report ${ }^{39}$ ) and whether NHS foundation trusts will increase their privately-paid income ${ }^{40}{ }^{41}$ towards the $49 \%$ limit. Again some studies associate 'possibility of competition' with higher efficiency ${ }^{42}$ and quality ${ }^{43-46}$ while others ${ }^{47-49}$ suggest the opposite. Neither body of research differentiates between provider types. The literature is also divided as to whether professional cultures vary between providers and the importance attaching to this. ${ }^{50-52}$

The scientific rationale of this study is therefore to extend and clarify previous research on provider diversification (not just competition). It will investigate multiple outcomes, analyse them longitudinally and trace them to organisational factors which produce any observed differences in behaviour between provider types, that is, differences in the outcomes which they produce as organisations and in the organisational means by which they produce those outcomes.

The policy rationale is to explore how the NHS and decision-makers within it, including clinicians who refer patients to other organisations, might exploit and influence that behaviour. This is important because the diversity of NHS providers is increasing. For example, private hospitals now do some $20 \%$ of NHS-funded hip and knee replacements, ${ }^{40}$ an estimated $31 \%$ of the $£ 9.7 \mathrm{bn}$ NHS funding of community health services in England in 2012-2013 was paid to non-NHS providers. ${ }^{53}$ Out-of-hours GP services in England are now mostly provided by social enterprises or commercial organisations. $^{54}$

Franchising NHS services to private providers excites Parliamentary ${ }^{55}$ and public ${ }^{56}$ debate. Reports and legislation (such as the Francis Report and the Care Act) are intended to shape provider behaviour irrespective of provider diversity. NHS Payments by Results are structured to promote quality rather than price competition. However, NHS commissioners' control over all types of provider is weakened by information asymmetry in the providers' favour, and commissioners' lack of managerial capacity. ${ }^{12}{ }^{13}$ Both the Commons Public Accounts Committee and the Audit Commission have considered whether more diverse provision may weaken provider accountability to (NHS) commissioners. ${ }^{57} 58$

This research aims to reduce this asymmetry by giving NHS commissioners more evidence-based knowledge as to which types of providers appear adapted to which market niches, the likely consequences of changing from one type of provider to another, where the managerial strengths and weaknesses of different types of provider lie, and which parts of NHS operational plans, contracts and guidance they tend to find easiest and hardest to comply with. That evidence should inform provider selection, alongside the monitoring (and if necessary, remedying) of provider performance. We hypothesise that the narrower provider freedoms are, the more uniform diverse providers' behaviour is likely to be in these respects. Conversely, variation is evidence of the extent to which providers have and use the freedoms which Liberating the NHS mentions. Evidence on these points would strengthen the evidence base for future guidance and health policy debates.

\section{RESEARCH QUESTIONS}

The strongest reason for expecting a diverse provider landscape to benefit the NHS is that diverse providers may deliver and develop services in different ways, creating variants from which NHS commissioners can select. Partly to test this assumption, we want to understand more about the effects and implications of provider diversification, and the mechanisms by which provider diversification has these effects. Our study therefore asks how the organisationally diverse providers of NHS-funded services vary in respect of:

1. Their responses to patients' and service users' rights to choose their healthcare provider, in those parts of the NHS quasi-market where providers compete to attract individual referrals and the payments that follow ('competition in markets')?

2. Responses to NHS commissioning changes, in those parts of the NHS quasi-market where providers compete for contracts to provide whole services ('competition for markets'), specifically, what:

A. Role providers play in service design?

B. Provider-commissioner interactions focus on (clinical outcomes, transactions and procurement, other matters)?

C. Responses local commissioner requirements (eg, accommodating changed referral patterns, collaboration with local authorities, targeting deprived populations) produce?

D. Responses national policy requirements (eg, the Fair Playing Field Review, or for productivity, 
impacts on outcomes, public involvement, transparency of provider activity) produce?

3. Use of information for commissioning purposes?

4. Providers':

A. Use of freedom to innovate (in particular, for NHS Foundation Trusts)?

B. Responses to potential innovations, speed of response and ensuing service changes?

5. Implications for commissioning and managerial practice which follow from the above, enabling the NHS to make better use of provider diversity.

\section{METHODS AND ANALYSIS}

\section{Design}

Since policy interventions are beyond researchers' control an observational study is the strongest feasible design. A focus on theory-driven qualitative methods is also required in order to understand how the different managerial regimes inside the 'black box' of the private or public firm influence behaviour. ${ }^{59}$ As a framework we will we use organisational theory, with institutional and transaction cost economics. ${ }^{60} 61$ Using that framework we will systematically compare different organisational types of provider. Our empirical focus will be on care groups that contain high proportions of older people at high risk of hospital admissions and readmissions, planned and unplanned. This will also enable us to examine how different provider types vary in terms of the patient journey across interorganisational interfaces. For primary care we focus on community health services (CHS) (district nursing, allied health professional services etc) and out-of-hours ( $\mathrm{OOH})$ GP services. We will examine hospital services both at whole-hospital level and in depth in certain specialities. Orthopaedics was an obvious choice but since it has already been studied we add ophthalmology. We will consider commissioning only in respect of how provider participation in commissioning differs (not commissioner structures or accountability, market entry and exit), and competition insofar as it exposes differences in provider behaviour.

The first strand of work is therefore a systematic comparison of organisational case studies of commissionerprovider interactions. Each case study will represent a different combination of provider type and services. The second strand is a qualitative tracer study of patient experience and choice, conducted in the same sites. We will draw on older patients with recent experience of each provider/service combination.

\section{Comparative organisational case studies}

By making and systematically comparing organisational case studies we will explore differences between and within provider types regarding:

1. Innovations: both internally-generated and externallymandated innovations, including any aimed at seldom heard and deprived care groups or populations and/or involving new uses of information.
2. Dealing with commissioners, focusing on providers' contribution to service design; participation in commissioning activity; engagement with the public; and response to inequalities of access and outcomes (eg, how providers and commissioners target seldom heard and deprived care groups or populations).

3. Information availability and use: whether different provider types use information differently when dealing with commissioners; how far the available information enables commissioners to compare provider performance with commissioners' requirements and other providers' performance (or offerings); any barriers to provider transparency and accountability (eg, compliance with Francis report recommendations).

Each 'case' (unit of analysis) will be one type of provider in one of four focal currently provided services (CHS, OOH or hospital specialty). Although this may change during the study period, each of these services currently has between three and five main provider types (a different selection for each service). This includes NHS Trusts and a growing number of hybrids (chiefly consortia established to deliver particular commissions). Table 1 shows which combinations of provider type and focal service are currently (early 2016) found in the English NHS.

To cover the most common variants thus implies at least 12 case studies. For each service we will make a purposive sample of Clinical Commissioning Groups (CCGs) that will together give us a maximum-variety sample of provider types. We will use our existing database developed for an earlier study ${ }^{13}$ and contacts with national organisations to select CCGs having low supply side concentration and high spending on non-NHS providers (markers for plural provision). As study sites, we will where possible select CCGs where we can co-locate more than one case study, for example, CCGs having more than one type of provider for a given service, so as to abstract from differences between local health system contexts and reduce research costs. Similarly, we will if possible select providers where we can co-locate case studies of more than one of the focal services. We will try to avoid sites already being researched for related projects.

We will identify key informants by snowballing from Chief Executives in provider organisations but expect that they will include a clinical director and, for commissioners, the contract manager with whom they deal directly. We will interview these informants using a semistructured interview schedule covering the themes noted above, observe the provider-commissioner meetings, and content-analyse the managerial documents indicated as seminal by the key informants. We will collect data during 2015-2017, both prospectively (in 'real time') about foreseeable changes in NHS requirements on providers (eg, revisions to QOF (Quality and Outcomes Framework), GP contracts, CQUIN (Commissioning for Quality and Innovation) and HRG 
Table 1 Combinations of provider type and focal service found in the English NHS in early 2016

Hospital Hospital Community health

orthopaedics

ophthalmology

services

GP out-of-hours

\section{Corporate \\ Proprietary \\ Not-for-profit \\ Public firm \\ Cooperative \\ Voluntary \\ Professional partnership}

White cells indicate combinations that currently exist, grey cells combinations not found

GP, general practitioner; NHS, National Health Service.

(Healthcare Resource Groups) tariffs; outcomes framework; high-priority NICE guidance) and retrospectively about recent major policy and/or environmental changes (eg, cuts in commissioner spending and CCGs' development as the main commissioners).

Using framework analysis, ${ }^{62}{ }^{63}$ we will collate these data and systematically compare provider types in order to establish:

1. How providers behave in response to externallyoriginated innovations, patients' demands, and commissioner requirements so as to indicate how different types of provider attempt to use their 'freedoms', as defined in post-2010 policy documents. ${ }^{2} 664$

2. How commissioners and regulatory bodies respond to providers' behaviour, indicating what 'freedoms' providers have in practice.

3. What information, and other media of control, ${ }^{13}$ providers and commissioners use during their interactions, including variations in how different types of provider use information.

4. How inequalities of access and outcome are dealt with.

The analytic framework will include a category for CCG-specific characteristics (eg, local decisions, local histories of provision), and we will compare published administrative data about the study sites characteristics against national patterns, to identify any differences study sites that reflect CCG rather than provider characteristics. We will also analyse the data inductively to reveal any patterns unforeseen by the researchers.

\section{Tracer studies of patient experience}

To trace patient experiences in the study sites, we will conduct qualitative research with patients and members of the public because they have privileged knowledge of patient choice ('competition in markets'), which has been a central policy rationale for provider diversity. As another policy outcome which may vary across different types of provider, we will assess whether commissioning decisions have become more democratically accountable, including the impacts of, and any changes in, patient and public involvement (PPI) arrangements.

To identify which aspects of choice are important to patients and any sensitivities, we will start by holding focus groups of representatives of patient organisations. We will use these groups to explore which aspects of service provision patients would like to have choices about; whether they actually have these choices; and how different organisations consult and/or involve patient organisations when decision-making. We will analyse participants' responses by induction from focus group transcripts, pooling data across focus groups on the assumption that patients' preferences about choice in a given service are independent of provider type. We will invite SW Peninsula CLAHRC Patient Involvement Group (PenPIG), Healthwatch and local groups indicated by the CCG and/or providers in the study sites, and (from websites or by snowballing) any other local groups involved with the services we are focusing on.

We will then interview patients who have used each case study service within the past 3 months (to reduce recall bias). Formal sampling calculations are not relevant to this type of exploratory qualitative research. We will interview patients until data saturation. Ideally we will identify patients by file-sampling providers' patient lists (excluding patients under 65 and/or receiving terminal care and/or with cognitive impairment). But if providers cannot accommodate this we will recruit patients through CCGs and their general practices. The interviews will be semistructured, using themes derived from the focus groups and published research. From the interview transcripts we will write, then systematically compare, tracer studies, ${ }^{65}$ reporting what choices patients were offered, which aspects of care were covered, patients' experiences of choice-making, and its consequences. Again we will analyse the data inductively to reveal any patterns unforeseen by the researchers.

In addition, we will set up an advisory panel, inviting representation from patient organisations. Its role will be to advise on important issues to focus attention on, methods and likely problems in collecting data for the patient tracer study, the website content and usability, and any other topics relevant to the project that they wish to raise. We will support the above involvement by meeting the participants' costs of participation (eg, travel costs) and paying an honorarium. 
Synthesising the organisational and patient studies

By collating these findings we will assemble a behavioural profile for each provider type, exploring which behaviours appear characteristic of, for example, foundation trusts, corporate providers, or social enterprises and how the local health economy context appears to influence that behaviour. Comparing these profiles will show the respects in which provider behaviour varies.

Attributing observed provider behaviour to a reform programme is inherently complex. In realist evaluation terms, current policy ${ }^{12} 7$ assumes that the mechanism by which provider diversification policy has its intended effects is:

1. Commissioners strengthen patient and public participation, focus attention on health outcomes and inequalities, and develop the infrastructure (eg, information systems) necessary to implement reform policies through commissioning.

2. They commission more diverse providers.

3. More diverse provider behaviour results in innovation, a concern for quality, better use of information, and greater responsiveness to patients' preferences.

4. This causes greater achievement of the policy outcomes ${ }^{1}$ above.

The methods we propose are thus intended to generate evidence of the extent to which the observed provider behaviours can be attributed to the reforms and present some diagnostic evidence should that attribution not be confirmed.

\section{ETHICS, BENEFIT AND DISSEMINATION}

The project has ethical approval (Ref. 15/EM/0089). We will obtain research governance permissions site by site. This is non-clinical research and the ethical complications of interviewing especially vulnerable people or informant deception do not arise. We will observe meetings only with the participants' consent. We will conduct patient and PPI in the same sites, providers and services as the organisational case studies. We will also include PPI as a research method by involving patients in refining research questions, providing data and advising the researchers. To preserve informant anonymity we will pseudonymise our informants and, where applicable, their organisations, and avoid definite descriptions (descriptions so specific that only one organisation matches them) in research reports and publications, unless we obtain informants' written permission not to. We will keep data that identify informants or their organisations in password-protected electronic storage with the option of encryption or (for paper) in locked cabinets in locked private offices.

Expected benefits from this research relate to commissioning and referral practice. We aim to enable NHS commissioners to select and make contracts with providers in a more informed way. This would include indicating which forms of monitoring (use of information) and incentives are most effective with different provider types. We also aim to inform provider development policy, by contributing to the evidence about, for example, which kinds of provider appear best qualified for particular roles in local health economies, and for the same reasons, help inform clinicians who, in making a referral, select a provider on behalf of their patient. This would help support an informed contestability of service provision. Similarly, such findings have potential to inform the organisational development of NHS foundation trusts and to inform competition policy by contributing evidence about the preferred market niches of different kinds of provider.

Our dissemination plans for patient informants will be shaped by PPI but are likely to include local meetings, probably, for practical reasons, one per study site. We will feed our findings back to managerial informants (who may include local authority and Health and Well-Being Board members) at face-to-face meetings. Our experience suggests that managers also appreciate opportunities to discuss the practical implications of research findings with peers elsewhere, so we will probably arrange a single workshop involving all such informants. We will submit presentations to national and regional conferences and organisations aimed at service providers, professional bodies and professional leaders, for instance the NHS Confederation. We will maintain a website publishing the main research findings. We will also submit papers to peer reviewed journals and to academic and scientific conferences, prioritising openaccess publication.

Contributors RS led the development of the original grant application and had responsibility for the conceptualisation of the study and protocol development, supported by ME, PA, SA, AG, RM and JH. RS and JH drafted this paper. All contributors approved the final draft.

Funding This study is funded under the Department of Health's Policy Research Programme (PR-X03-1113-11005).

Competing interests None declared.

Ethics approval MREC ethical approval (Reference 15/EM/0089, 17 February 2015).

Provenance and peer review Not commissioned; externally peer reviewed.

Open Access This is an Open Access article distributed in accordance with the Creative Commons Attribution Non Commercial (CC BY-NC 4.0) license, which permits others to distribute, remix, adapt, build upon this work noncommercially, and license their derivative works on different terms, provided the original work is properly cited and the use is non-commercial. See: http:// creativecommons.org/licenses/by-nc/4.0/

\section{REFERENCES}

1. Department of Health. Equity and excellence: liberating the NHS London: Department of Health, 2010. Report No.: Cm 7881.

2. Department of Health. NHS Choice Framework 2015 to 2016 London: Department of Health, 2016 (cited 1 Feb 2016). https:// www.gov.uk/government/publications/nhs-choice-framework2015-to-2016.

3. Sheaff R. Plural provision of primary medical care in England, 20022012. J Health Serv Res Policy 2013;18 2):20-8.

4. Alexander J, Nank R. Public--nonprofit partnership: realizing the new public service. Administration Society 2009;41:364-86. 
5. Sheaff R, Child S, Schofield J, et al. Understanding professional partnerships and non-hierarchical organisations. London: NIHR-SDO, 2012

6. NHS Commissioning Board. The NHS Standard Contract: a guide for clinical commissioners. London: NHS Commissioning Board, 2013 (cited 1 Feb 2016). https://www.england.nhs.uk/?s=prime +contractor

7. NHS England. Five year forward view. London: NHS England, 2014

8. Mahar M. Money driven medicine: the real reason health care costs so much. New York: Collins, 2006.

9. Alexander J. Adaptive Strategies of Nonprofit Human Service Organizations in an Era of Devolution and New Public Management. Nonprofit Manag Leadersh 2000;10:287-303.

10. Hvidman U, Andersen SC. Impact of performance management in public and private organizations. J Public Adm Res Theory 2014;24:35-58

11. Johansen M, Zhu L. Market competition, political constraint, and managerial practice in public, nonprofit, and private American hospitals. J Public Adm Res Theory 2014;24:159-84.

12. Bartlett $\mathrm{W}$, Allen $\mathrm{P}$, Pérotin $\mathrm{V}$, et al. Provider diversity in the NHS: impact on quality and innovation. London: Health Reform Evaluation Programme (HREP), 2012

13. Sheaff $\mathrm{R}$, Charles N, Mahon A, et al. NHS commissioning practice and health system governance: a mixed-methods realistic evaluation. Health Serv Deliv Res 2015;3:1-184.

14. Horwitz JR. Making profits and providing care: comparing nonprofit, for-profit, and government hospitals. Health Aff 2005;24:790-801.

15. Rosenau PV, Linder SH. Two decades of research comparing for-profit and nonprofit health provider performance in the United States*. Soc Sci Q 2003;84:219-41.

16. Clement J, White K, Valdmanis V. Charity care: do not-for-profits influence for-profits? Med Care Res Rev 2002;59:59-78.

17. Devers KJ, Brewster LR, Casalino LP. Changes in hospital competitive strategy: a new medical arms race? Health Serv Res 2003;38(Pt 2):447-69.

18. Devereaux PJ, Heels-Ansdell D, Lacchetti C, et al. Payments for care at private for-profit and private not-for-profit hospitals: a systematic review and meta-analysis. CMAJ 2004;170:1817-24.

19. Cutler D, Horwitz J. Converting hospitals from not-for-profit to for-profit status. why and what effects? In: Cutler D. ed. The changing hospital industry: comparing for-profit and not-for-profit institutions. Chicago: University of Chicago Press, 2000:45-90.

20. Guyatt G, Devereaux PJ, Lexchin J, et al. A systematic review of studies comparing health outcomes in Canada and the United States. Open Med 2007:1:27-36.

21. Chambers N, Sheaff R, Mahon A, et al. The practice of commissioning healthcare from a private provider: learning from an in-depth case study. BMC Health Serv Res 2013;13(Suppl 1):S4

22. Bevan G. Have targets done more harm than good in the English NHS? No. BMJ 2009;338:a3129.

23. Comptroller and Auditor General. The role of major contractors in the delivery of public services. London: National Audit Office, 2013. Report No: HC810.

24. Porter A, Mays N, Shaw S, et al. Commissioning healthcare for people with long term conditions: the persistence of relational contracting in England's NHS quasi-market. BMC Health Serv Res 2013;13(Suppl 1):S2.

25. Audit Commission, Healthcare Commission. Is the treatment working? Progress with the NHS system reform programme. London: Audit Commission, 2008.

26. Drevs F, Tscheulin DK, Lindenmeier J. Do patient perceptions vary with ownership status? A study of nonprofit, for-profit, and public hospital patients. Nonprofit Voluntary Sector Q 2014;43:164-84.

27. Devereaux PJ, Schunemann HJ, Ravindran N, et al. Comparison of mortality between private for-profit and private not-for-profit hemodialysis centers: a systematic review and meta-analysis. JAMA 2002:288:2449-57.

28. Comondore VR, Devereaux PJ, Zhou Q, et al. Quality of care in for-profit and not-for-profit nursing homes: systematic review and meta-analysis. BMJ 2009;339:b2732.

29. Pérotin V, Zamora B, Reeves R, et al. Does hospital ownership affect patient experience? An investigation into public-private sector differences in England. J Health Econ 2013;32:633-46.

30. Greenhalgh T, Robert G, Macfarlane F, et al. Diffusion of innovations in service organizations: systematic review and recommendations. Milbank Q 2004;82:581-629.

31. Newton J, Graham J, McLoughlin K, et al. Receptivity to change in a general medical practice. Br J Manag 2003;14:143-53.

32. Butler M. Managing from the inside out: drawing on 'receptivity' to explain variation in strategy implementation. Br J Manag 2003;14 (Suppl):S47-60.
33. Beckert W, Christensen M, Collyer K. Choice of NHS-funded Hospital Services in England. Econ J 2012;122:400-17.

34. Reay $\mathrm{T}$, Hinings $\mathrm{CR}$. Managing the rivalry of competing institutional logics. Organ Stud 2009;30:629-52.

35. Pache A-C, Santos F. Inside the Hybrid Organization: selective coupling as a response to competing institutional logics. Acad Manage J 2013;56:972-1001.

36. Potter SJ. A longitudinal analysis of the distinction between for-profit and not-for-profit hospitals in America. J Health Soc Behav 2001;42:17.

37. Schmid A, Ulrich V. Consolidation and concentration in the German hospital market: the two sides of the coin. Health Policy 2013;109:301-10.

38. Eggleston K, Shen YC, Lau J, et al. Hospital ownership and quality of care: what explains the different results in the literature? Health Econ 2008;17:1345-62.

39. The Mid Staffordshire NHS Foundation Trust Inquiry. Independent Enquiry into the Care Provided by Mid Staffordshire NHS Foundation Trust 2005-2009. London: HMSO, 2010.

40. Competition Commission. Private healthcare market investigation. London: Competition Commission, 2013.

41. Exworthy M, Frosini F, Jones L. Are NHS foundation trusts able and willing to exercise autonomy? 'You can take a horse to water...' $J$ Health Serv Res Policy 2011;16:232-7.

42. Dranove $\mathrm{D}$, White WD. Recent theory and evidence on competition in hospital markets. J Econ Manag Strategy 1994;3:169-209.

43. Cooper Z, Gibbons S, Jones S, et al. Does Hospital Competition Save Lives? Evidence From The English NHS Patient Choice Reforms. Econ J (London) 2011;121:F228-60.

44. Gaynor M, Moreno-Serra R, Propper C. Can competition improve outcomes in UK health care? Lessons from the past two decades. $J$ Health Serv Res Policy 2012;17(Suppl 1):49-54.

45. Bloom N, Propper C, Seiler S, et al. The impact of competition on management quality: evidence from public hospitals. London: LSE, 2010. Report No.: 983.

46. Propper C, Burgess S, Gossage D. Competition and Quality: evidence from the NHS Internal Market 1991-9. Econ J 2008;118:138-70

47. Pollock A, Macfarlane A, Kirkwood G, et al. No evidence that patient choice in the NHS saves lives. Lancet 2011;378:2057-60.

48. Player S, Leys C. Confuse and conceal: the NHS and independent sector treatment centres. Monmouth: Merlin, 2008.

49. Yates J. Private eye, heart and hip: surgical consultants, The National health service and private medicine. Edinburgh: Churchill Livingstone, 1995.

50. Bevan G. Impact of devolution of health care in the UK: provider challenge in England and provider capture in Wales, Scotland and Northern Ireland? J Health Serv Res Policy 2010;15:67-8.

51. Andersen LB, Jakobsen M. Does ownership matter for the provision of professionalized services? Hip operations at publicly and privately owned clinics in Denmark. Public Adm 2011;89: 956-74.

52. Waring J, Bishop S. Healthcare identities at the crossroads of service modernisation: the transfer of NHS clinicians to The Independent sector? Soc Health IIIn 2011;33:661-76.

53. Laing W. Primary care and out-of-hospital services UK market report. 2nd Edn. London: LaingBuisson, 2015.

54. National Audit Office (NAO). Out-of-hours GP services in England London: National Audit Office, 2014 (cited 14 Dec 2015). Report No.: HC 439 https://www.nao.org.uk/report/hours-gp-servicesengland-2/

55. House of Commons Committee of Public Accounts. Department of Health: The Franchising of Hinchingbrooke Health Care NHS Trust and Peterborough and Stamford Hospitals NHS Foundation Trust. London: House of Commons, 2013. Report No.: HC789.

56. Kenny C. Public turns against NHS use of private providers. Pulse 2013. http://www.pulsetoday.co.uk/hot-topics/practice-news/publicturns-against-nhs-use-of-private-providers/20005345.fullarticle

57. House of Commons Committee of Public Accounts. The provision of the out-of-hours GP service in Cornwall. London: HMSO, 2013. Report No.: HC 471 [Incorporating HC 1105, Session 2012-13].

58. National Audit Office. The role of major contractors in the delivery of public services. London: National Audit Office, 2013. Report No.: HC 810. Sesslon 2013-14.

59. Walach $\mathrm{H}$, Falkenberg $\mathrm{T}$, Fønnebø V, et al. Circular instead of hierarchical: methodological principles for the evaluation of complex interventions. BMC Med Res Methodol 2006:6:29.

60. Williamson O. The economic institutions of capitalism. New York: Free Press, 1985.

61. Hansmann H. The ownership of enterprise. Cambridge, USA Harvard UP, 1996. 
62. Ritchie J, Spencer L. Qualitative analysis for applied social theory In: Bryman A, Burgess R, eds. Analysing qualitative data. London: Routledge, 1994:173-94.

63. Gale NK, Heath G, Cameron E, et al. Using the framework method for the analysis of qualitative data in multi-disciplinary health research. BMC Med Res Methodol 2013;13:117.
64. Almeida C, Travassos C, Porto S, et al. Health sector reform in Brazil: a case study of inequity. Int $J$ Health Serv 2000;30: 129-62.

65. Symon G, Long K, Ellis J. The coordination of work activities: cooperation and conflict in a hospital context. Comput Supported Cooperative Work (CSCW) 1996;5:1-31. 